\title{
ASPECTOS MEMORIALÍSTICOS E IDENTITÁRIOS PRESENTES NOS ENUNCIADOS DAS GANHADEIRAS DE ITAPUÃ: RESSIGNIFICAÇÃO DA MEDIAÇÃO CULTURAL NO DISPOSITIVO DE COMUNICAÇÃO DA WEB
}

\author{
MEMORIALISTIC AND IDENTITY ASPECTS PRESENT IN \\ THE STATEMENTS OF GANHADEIRAS DE ITAPUÃ: \\ REDEFINITION OF CULTURAL MEDIATION IN THE WEB \\ COMMUNICATION DEVICE
}

\author{
Raquel do Rosário Santos ${ }^{a}$ \\ Ana Claudia Medeiros de Sousab
}

\begin{abstract}
RESUMO
Introdução: Os dispositivos de comunicação favorecem a mediação cultural, porque potencializam, para além do tempo e do espaço geográfico, o acesso às informações, carregadas de sentidos e de valor memorialístico e que constituem a história dos sujeitos. Objetivo: Investigar se os enunciados disponíveis no dispositivo de comunicação da web das Ganhadeiras de Itapuã contribuem para ressignificar os traços identitários e memorialísticos do meio em que suas práticas sociais são desenvolvidas e para mediar a cultura. Metodologia: Quanto aos procedimentos de coleta dos dados, adotou-se a técnica de observação indireta, para identificar os conteúdos disponibilizados no Facebook das Ganhadeiras de Itapuã. A amostra foi relativa às publicações de janeiro a dezembro de 2019. Foram selecionadas postagens mais representativas do contexto social em que essas mulheres estão inseridas. Os dados foram analisados empregando-se a abordagem qualitativa, que favoreceu o processo de interpretação dos dados coletados. Resultados: Constatou-se que o dispositivo de comunicação da web social das Ganhadeiras de Itapuã potencializa a mediação cultural para além do território baiano, porquanto contribuem para que as manifestações identitárias e memorialísticas desse grupo sejam reconhecidas e, de maneira consciente, promove a construção dialógica no âmbito da diversidade de pensamentos, de ideologias e de crenças. Conclusões: $O$ estudo mostrou que o dispositivo de comunicação das Ganhadeiras de Itapuã é um ambiente propício para mediar a cultura, a informação e a leitura, bem como para descortinar traços de memória e de identidade

a Docente do Departamento de Documentação e Informação do Instituto de Ciência da Informação da Universidade Federal da Bahia. Doutora em Ciência da Informação pela Universidade Federal da Paraíba. Email: quelrosario@gmail.com

b Docente do Departamento de Documentação e Informação do Instituto de Ciência da Informação da Universidade Federal da Bahia. Doutora em Ciência da Informação pela Universidade Federal da Paraíba. Email: ana.violista@gmail.com
\end{abstract}


da mulher negra.

Descritores: Memória. Identidade. Mediação cultural. Dispositivo de comunicação da web. Ganhadeiras de Itapuã.

\title{
1 INTRODUÇÃO
}

\author{
"No cheiro da aroeira \\ A sombra pra descansar \\ História das ganhadeiras \\ Que nós viemos contar" \\ História Das Ganhadeiras \\ As Ganhadeiras de Itapuã
}

Os enunciados presentes nos diversos dispositivos de comunicação subsidiam a reflexão sobre os vestígios de memória e identidade de um indivíduo e/ou de grupos sociais e podem fazer com que transpareçam suas ideologias, suas crenças, seus costumes etc. Nesse contexto, o mediador cultural é um agente que reconhece os enfrentamentos $e$ as diferentes manifestações identitárias e memorialísticas e, conscientemente, possibilita a construção dialógica no âmbito da diversidade de pensamentos.

Os dispositivos de comunicação favorecem a mediação cultural, porque potencializam, para além do tempo e do espaço geográfico, o acesso às informações, carregadas de sentidos e de valor memorialístico e que constituem a história dos sujeitos. Assim, por meio dos dispositivos de comunicação da web podem-se disseminar e preservar os referenciais de memória considerados como bens patrimoniais.

A partir dessa reflexão, esta pesquisa teve o objetivo de investigar se os enunciados disponíveis no dispositivo de comunicação da web das Ganhadeiras de Itapuã contribuem para ressignificar os traços identitários e memorialísticos do meio em que suas práticas sociais são desenvolvidas e para promover a mediação da cultura. Sob o ponto de vista da metodologia, a pesquisa se configura como descritiva e documental, e seu objeto de estudo é a página das Ganhadeiras de Itapuã no Facebook. A escolha por esse objeto se justifica por causa da representatividade das Ganhadeiras de Itapuã para a cultura baiana e o empoderamento da mulher negra. 
Conforme evidenciado no documentário realizado pela TV da Universidade Federal da Bahia, em 2015, as Ganhadeiras de Itapuã é um grupo cultural e musical que tem o objetivo de resgatar, valorizar e fortalecer a riqueza da identidade cultural fortemente ligada a um dos bairros tradicionais de Salvador, Itapuã. Ainda de acordo com o documentário supracitado, a iniciativa surgiu nos terreiros das casas de Dona Cabocla e de Dona Mariinha, onde um grupo de mulheres se reunia semanalmente para trocar informações sobre as antigas tradições do lugar. O nome "Ganhadeiras de Itapuã" é uma homenagem às mulheres que no século XIX e XX compravam os peixes na mão dos pescadores locais, tratavam, empalhavam, e saíam com seus balaios a pé até 0 centro da cidade de Salvador para venderem os seus produtos e ganharem o sustento da família, assim como àquelas que lavavam roupas à beira da Lagoa do Abaeté e tinham nessa atividade o sustento de suas famílias.

Os resultados evidenciaram que o dispositivo de comunicação da web social das Ganhadeiras de Itapuã potencializa a mediação cultural para além do território baiano, promove o reconhecimento das manifestações identitárias e memorialísticas desse grupo e, de maneira consciente, possibilita a construção dialógica no âmbito da diversidade de pensamentos, de ideologias e de crenças. A figura da mulher negra, como símbolo de resistência e de empoderamento, a musicalidade, a religiosidade, a dança, a culinária e os figurinos, entre outros elementos, são apresentados como constituintes da memória e da identidade de um povo que se fortalece durante o tempo e mantém viva, por meio da tradição e da apresentação desses elementos memorialísticos, sua identidade.

\section{MEMÓRIA E IDENTIDADE NAS PRÁTICAS DE MEDIAÇÃO CULTURAL: OS DISPOSITIVOS DE COMUNICAÇÃO NA WEB COMO POTENCIALIZADORES DAS MANIFESTAÇÕES CULTURAIS}

O interesse pela memória se manifesta de várias maneiras, por meio da afeição pelos referenciais de memória considerados bens patrimoniais, porque, "[...] sem memória, o sujeito furta-se, vive unicamente no instante, perde suas capacidades conceituais e cognitivas [...] e sua identidade desvanece-se" 
(CANDAU, 2013, p. 10).

Desde os primórdios das relações sociais que o homem deixa vestígios nos mais diversos suportes informacionais, produzindo artefatos que transparecem a constituição de sua memória. Para tanto, utilizou e ainda utiliza vários dispositivos de comunicação, como os desenhos, a oralidade, a escrita, as expressões artísticas e, mais recentemente, tem utilizado os recursos da web para registrar informações que caracterizam culturas, costumes, descobertas etc. Nesse contexto, "[...] a necessidade de memória não passa apenas pela identificação do ser como vivente, mas revela-se como uma transcendência à vida terrena. Uma vontade supraobjetiva de ligação a elos do passado que subsistirão no futuro, garantindo, assim, a eternidade" (DODEBEl, 1997, p. 48). Com essa reflexão, pode-se inferir que os dispositivos de comunicação são sobremaneira relevantes, porque contribuem para preservar e delinear a memória de determinado indivíduo e/ou grupo social. Ainda de acordo com a autora,

[...] como o homem habita o espaço cultural que ele próprio cria e transforma continuamente, ele necessita utilizar o passado como marco referencial e auto-identificador. O patrimônio cultural passa a ser entendido como o conjunto de informações que caracterizam as ordens de significado dentro de um grupo, povo ou nação. (DODEBEI, 1997, p. 44).

Todo indivíduo é dotado de memória, que resulta de uma organização neurobiológica e é somada com a coletividade e a estrutura sociocultural, ou seja, há necessidade do outro, posto que a memória é uma construção social que, de certa maneira, sempre acontece "[...] no quadro de uma relação dialógica com o Outro" (CANDAU, 2012, p. 9). O indivíduo e os grupos sociais estão envolvidos nas práticas sociais e nas manifestações culturais de seu meio, que propiciam a produção de referenciais de memória que revelam seus traços identitários e dependem delas.

Pollack (1992, p. 212) compreende que

[...] a memória é um elemento constituinte do sentido de identidade, tanto individual como coletiva, na medida em que ela é também um fator extremamente importante do sentido de continuidade e de coerência de uma pessoa ou de um grupo em sua reconstrução de si.

Os referenciais de memória são essenciais para caracterizar os indícios 
de identidade de um indivíduo e/ou grupo social, a fim de resguardar-lhes a memória. Candau (2012) compreende que a memória é a identidade em ação, em um jogo que envolve lembranças e esquecimentos e que é responsável pelo sentimento de identidade. Como afirma o autor, a memória alimenta a identidade. Nesse ponto, é válido citar o papel dos dispositivos de comunicação para fortalecer a mediação cultural ao contribuir para disseminar e preservar os referenciais de memória considerados como bens patrimoniais.

Patrimônio é tudo o que a humanidade possui de melhor e pode ser um bem material tangível ou intangível. É, ainda, uma referência para formar a identidade de um indivíduo e/ou grupo. O patrimônio é selecionado pelos próprios grupos sociais, que têm o poder de decidir o que deve ser lembrado ou esquecido. Para Candau (2013, p. 148), "[...] o patrimônio é o produto de um trabalho de memória". Como se pode notar, existem enlaces que envolvem a memória, a identidade e o patrimônio que são capazes de viabilizar a caracterização da diversidade cultural de um povo, por meio das relações entre os referencias de memória e os enunciados.

Assim, os referenciais de memória materializam enunciados que são dependentes em um jogo enunciativo, uma vez que "[...] o enunciado aparece como um elemento último, indecomponível, suscetível de ser isolado em si mesmo e capaz de entrar em um jogo de relação com outros elementos semelhantes a ele" (FOUCAULT, 1987, p. 90). O enunciado não é autônomo, livre ou neutro, porquanto está continuamente conectado em rede, seja como uma série ou conjunto, compondo-se e/ou apoiando-se em outros, seja se diferenciando deles (FOUCAULT, 1987).

Os elementos constituintes da identidade de um indivíduo ou de grupos sociais são transcritos em enunciados materializados nos referenciais de memória, que transparecem a estrutura sociocultural em que são produzidos e podem evidenciar informações representativas de seus produtores, já que a identidade molda a maneira como o indivíduo se comporta, define-o e modela-o (CANDAU, 2013). Portanto, para o autor, não existe identidade sem memória e,

[...] inversamente, não pode haver memória sem identidade, porque a conexão dos estados sucessivos que o sujeito conhece é impossível se este não tem consciência a priori de que este 
encadeamento de seqüências temporais pode ter uma significação (CANDAU, 2013, p. 143).

Assim como a memória é determinada pela identidade - porque a identidade sólida, com tradições, costumes e rituais, é essencial para tornar uma memória forte - a identidade está relacionada à maneira como o indivíduo interage com as tradições, com as crenças e com as ideologias do seu grupo social. Assim, tanto a memória quanto a identidade são construídas por meio das práticas socioculturais dos grupos em seu meio, em que estão sujeitas à lembrança e ao esquecimento, portanto, devem ser preservadas para evitar seu silenciamento.

Retomando a reflexão apresentada por Candau (2013), convém refletir sobre a palavra moldar que, no contexto sobre identidade, pode ser interpretada como movente, de movimento. Isso significa que os sujeitos, o tempo todo, podem ter acesso a novas interpretações sobre sua cultura e dirigir um olhar crítico sobre quem ele é no seu grupo e a representatividade dos traços identitários que o constituem. Nesse processo de contínuo crescimento como ser social, ele pode atuar como protagonista cultural, demonstrar novas maneiras de se relacionar com o meio e transformar a si mesmo, aos outros e as suas ações. Entretanto, acredita-se que essa ação protagonista não acontece de maneira instantânea ou dissociada de elementos materiais e imateriais, portanto de dispositivos culturais e do processo de interferência do mediador na relação intrapessoal e interpessoal que o sujeito realiza com esses dispositivos, com outros sujeitos e com os meios culturais.

Nesse sentido, entende-se a mediação cultural a partir da reflexão de Perrotti (2016, p. 13), para quem essa ação

[...] emerge na contemporaneidade como formulação teórica e metodológica inscrita, portanto, num quadro que reconhece os conflitos, ao mesmo tempo que a necessidade de estabelecimento de elos que viabilizem diálogos necessários à geração de ordens culturais mais democráticas e plurais.

O mediador cultural é um agente que reconhece os enfrentamentos e as diferentes manifestações identitárias e memorialísticas do seu meio, apresenta conscientemente os elementos referenciais e possibilita a construção dialógica no âmbito da diversidade de pensamentos. Então, a mediação cultural age 
contra o apagamento e o silenciamento da liberdade de expressão e contribui para fortalecer os traços de memória e de identidade presentes nos bens patrimoniais.

Assim, a mediação cultural manifesta-se

[...] na diversidade que caracteriza o espaço público, sem silenciar conflitos nem vozes discordantes, sem isolar ou impedir a emergência da pluralidade, das tensões que lhe são próprias, a mediação cultural apresenta-se, pois, como um território discursivo, de embates e possibilidades, ao mesmo tempo que de afirmação da esfera pública como instância superior organizadora e legitimadora do campo simbólico. (PERROTTI, 2016, p. 13)

Com base nessa análise, reitera-se que, quando a mediação cultural é realizada de maneira consciente, fortalece e empodera os diversos grupos sociais. Para isso, essa ação deve ser considerada, ampliada e realizada pelos diversos agentes em seu meio, inclusive nos espaços digitais. As ações de mediação cultural podem ser potencializadas usando-se os recursos digitais e os dispositivos de comunicação na web. Assim, os sujeitos podem interagir com os ambientes informacionais, sociais e culturais e compartilhar conhecimentos, aspectos ligados à cultura, aos saberes e às crenças das comunidades, com o fim de empoderar os que pertencem ao meio e fortalecer a empatia, visto que podem compreender a história de vida do outro e a alteridade, reconhecer suas diferenças e respeitá-las. Dessa maneira, a web social e seus dispositivos de comunicação podem ser fortes aliados nessa interação, ampliar o processo de comunicação e de compartilhamento dos conhecimentos e proporcionar um ambiente propício para a mediação cultural.

O termo dispositivo é adotado nesta pesquisa sob o ponto de vista de Pieruccini (2007), que o entende como "[...] um signo, um mecanismo de intervenção sobre o real, que atua por meio de formas de organização estruturada, utilizando-se de recursos materiais, tecnológicos, simbólicos e relacionais, que atingem os comportamentos e condutas afetivas, cognitivas e comunicativas dos indivíduos." Portanto, como os recursos de comunicação na web, também conhecidos como mídias sociais online, redes sociais digitais, entre outros termos, interferem no comportamento dos sujeitos, em sua forma de interagir e de atuar de maneira ativa nesse processo, são reconhecidos como 
dispositivos de comunicação.

Os dispositivos de comunicação na web potencializam as redes de interação e comunicação entre os sujeitos - as denominadas redes sociais - que, no ambiente da web, tornam-se agrupamentos virtuais utilizados para fins profissionais, de entretenimento, políticos, entre tantos outros, onde os sujeitos conseguem produzir conteúdos e disseminar e agregar conhecimentos (RIBEIRO; LEITE; LOPES, 2014).

Primo $(2007$, p. 7$)$ defende que "[...] uma rede social online não se forma pela simples conexão de terminais. Trata-se de um processo emergente, que mantém sua existência através de interações entre os envolvidos." Dessa maneira, uma rede social online não se amplia e se fortalece somente com a troca de conteúdos que os sujeitos realizam entre si, mas também por meio da interação com essa ação. Ainda conforme o autor, "[...] a interação social é caracterizada não apenas pelas mensagens trocadas (o conteúdo) e pelos interagentes que se encontram em dado contexto (geográfico, social, político, temporal), mas também pelo relacionamento que existe entre eles" (PRIMO, 2007, p. 7). Ele acrescenta que "[...] tal relacionamento apresenta reciprocidade (uma compreensão equivalente dos interagentes sobre a natureza e qualidade de seu relacionamento), intensidade e intimidade (a familiaridade entre eles)" (PRIMO, 2007, p. 8, grifo nosso).

Nesse contexto, defende-se que o uso dos dispositivos de comunicação na web pelos agentes mediadores pode tornar conhecidos os bens culturais que os representam. Eles também são apropriados pelos sujeitos que neles se reconhecem. Assim, facebook, blog, twitter, instagram, entre outros dispositivos de comunicação, podem ser um ambiente propício para a mediação cultural.

\section{METODOLOGIA}

Esta comunicação se configura como descritiva, porque visou descrever as características de determinada população (GIL, 2002), cujo objeto de investigação foi um dispositivo de comunicação da web das Ganhadeiras de Itapuã, mais especificamente, o Facebook, e como documental, que é uma "[...] 
fonte rica e estável de dados. Como os documentos subsistem ao longo do tempo, tornam-se a mais importante fonte de dados em qualquer pesquisa de natureza histórica" (GIL, 2002, p. 46).

O objetivo geral desta pesquisa foi de investigar se os enunciados disponíveis no dispositivo de comunicação da web das Ganhadeiras de Itapuã favorecem a ressignificação dos traços identitários e memorialísticos do meio em que suas práticas sociais são desenvolvidas e contribuir para promover a mediação cultural.

Para a coleta dos dados, adotou-se a técnica de observação indireta, por meio da qual foi possível identificar os conteúdos disponibilizados no Facebook das Ganhadeiras de Itapuã. A amostra envolveu as publicações de janeiro a dezembro de 2019. Foram selecionadas as postagens mais representativas do contexto social em que as Ganhadeiras de Itapuã estão inseridas. A apresentação e a interpretação dos dados se concentraram nas informações contidas na referida rede social. Para isso, foi adotada a abordagem qualitativa.

\section{APRESENTAÇÃO E ANÁLISE DOS DADOS}

A partir da observação indireta dos conteúdos disponibilizados na página do Facebook das Ganhadeiras de Itapuã, constatou-se que existe uma preocupação em apresentar a origem e a história dessas mulheres e suas contribuições em diferentes períodos históricos do Brasil. Há, ainda, considerações a respeito do grupo musical, que começou nos encontros de senhoras moradoras do Bairro de Itapuã, Salvador - BA, que se reuniam para rememorar as práticas socioculturais do bairro, como: as festas religiosas e as profanas, as cantigas, as brincadeiras, as lavagens de ganho da Lagoa do Abaeté, a pesca, as vendas de cocadas etc. Nessas reuniões, cantavam e contavam histórias de suas mães, avós e bisavós, cuja maioria trabalhava de "ganho". Em meio a essas lembranças, foi formado o grupo As Ganhadeiras de Itapuã.

A web social possibilita que as Ganhadeiras de Itapuã narrem suas histórias de maneira coletiva ou individual, independentemente da idade, 
destacando a geração e a relação familiar de cada uma delas. Esses conteúdos foram disponibilizados em formato textual, audiovisual e iconográfico. Esses recursos foram empregados individual ou simultaneamente e elaborados pelos produtores da página ou por outras instituições, como as universidades, por exemplo. Assim, os conteúdos demonstram a afetividade e a relação individual e coletiva do grupo, evidenciando o que foi defendido por Candau (2012) - que a memória individual é constituída em um quadro de relação dialógica com o Outro.

Além da representação identitária, em que é apresentada cada uma das mulheres e das meninas que integram as Ganhadeiras de Itapuã, as postagens deixam clara a preocupação com a mulher de maneira geral. Conteúdos comemorativos, como o Dia Internacional da Mulher ou sobre o "Outubro rosa", mês de conscientização da prevenção ao câncer de mama, demonstram o cuidado e o valor da figura feminina para esse grupo de mulheres. Assim, podese inferir que, além de suas crenças, seus costumes e seus valores culturais, as mulheres podem se sentir representadas e acolhidas ao ver esses tipos de conteúdo, porque demonstram um incentivo ao empoderamento feminino.

Vinculado ao sentimento de empoderamento, há um conteúdo sobre a comemoração ao dia 20 de novembro, Dia da Consciência Negra, conforme ilustrado na Figura 1, em que a mulher negra é representada como sinônimo de resistência social. É importante destacar a relação entre as imagens das quatro mulheres, de diferentes idades, com roupas e acessórios que evocam os traços da cultura africana, representativa dos seus antepassados, pois, como compreende Dodebei (1997), o sujeito habita o espaço cultural e utiliza o passado como marco referenciador. 
Figura 1 - Postagem das Ganhadeiras de Itapuã no Dia da Consciência Negra

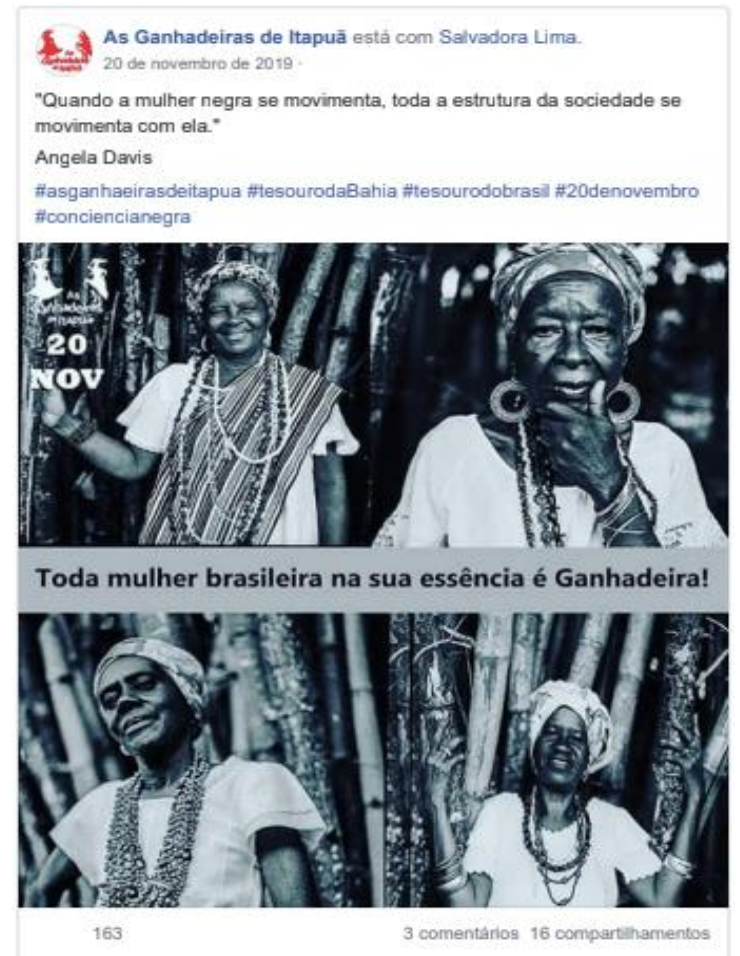

Fonte: https://www.facebook.com/AsGanhadeirasdeltapua/

A Figura 1 traz a citação de Angela Davis, uma militante dos direitos da mulher e contra a discriminação racial, referenciada por muitos pesquisadores em suas publicações científicas. A frase pode ser entendida como um estímulo ao empoderamento e à força da mulher negra na constituição da sociedade brasileira. Por fim, além dos elementos citados, a postagem, no centro da imagem, evidencia o autorreconhecimento das Ganhadeiras de Itapuã para a cultura brasileira. Assim, a figura feminina é eleita para comemorar um dia de conscientização identitária, com o fim de retomar e valorizar aspectos memorialísticos do povo negro.

Os indícios de religiosidade das Ganhadeiras estão presentes nas postagens, conforme ilustra a Figura 2, em que fazem uma prece a Yemanjá, orixá importante da religião afrodescendente. 


\section{Figura 2 - Postagem das Ganhadeiras de Itapuã no Dia de Yemanjá}

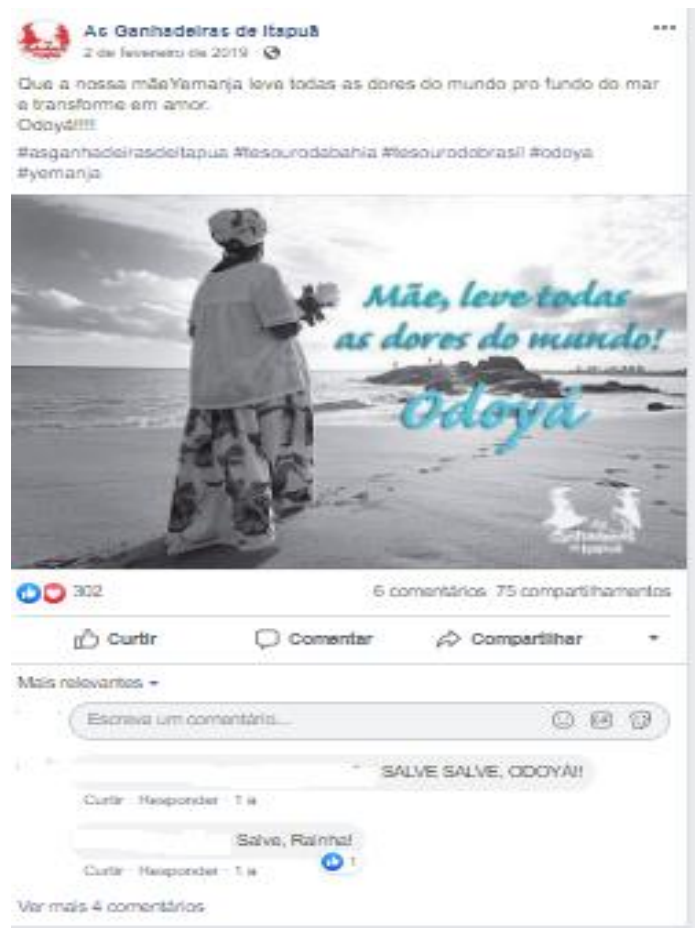

Fonte: https://www.facebook.com/AsGanhadeirasdeltapua/

No Brasil, as religiões de matriz africana ainda enfrentam conflitos e discriminação. Nesse contexto, o dispositivo de comunicação da web possibilita uma apresentação harmônica das crenças e dos costumes herdados do povo negro, trazidos do continente africano para o Brasil, onde foram escravizados e proibidos de professar seus atos de fé. Assim, por meio do agente mediador e do dispositivo de comunicação na web, que potencializam a mediação cultural para além do território baiano, onde diferentes manifestações religiosas são cultuadas, é possível reconhecer as diferentes manifestações identitárias e memorialísticas do seu meio e, de maneira consciente, promover uma construção dialógica no âmbito da diversidade de pensamentos, de ideologias e de crenças.

A Figura 3 também mostra uma ação de mediação cultural, em que a história do povo negro é evidenciada, como sua culinária e os cultos religiosos, porquanto o alimento é utilizado como oferenda. Esse processo transparece os traços constitutivos da memória e da identidade desse povo e de suas práticas. Esse tipo de mediação cultural reforça o que defende Perrotti (2016) sobre o agir 
na diversidade como um território discursivo e com possibilidades de legitimar o campo simbólico.

Figura 3 - Postagem das Ganhadeiras de Itapuã sobre o acarajé

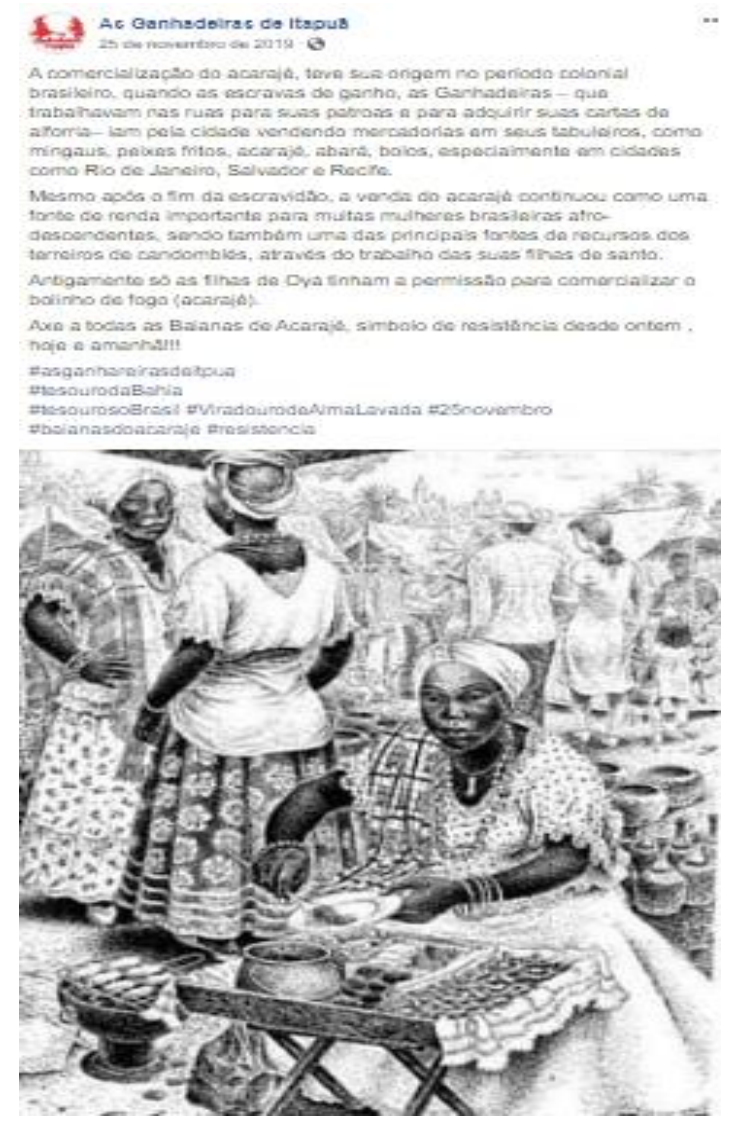

Fonte: https://www.facebook.com/AsGanhadeirasdeltapua/

O enunciado dessa postagem, apresentado tanto na escrita quanto na imagem, reitera os aspectos culturais identificados na culinária e na figura da baiana, que vende suas iguarias no tabuleiro que foram reproduzidas seguindo a tradição de seus antepassados, o que fortalece, no presente, a identidade desse povo. Esse dado nos remete ao pensamento de Dodebei (1997) de que é necessária uma ligação com o passado, como marco identificador no presente, para subsidiar o futuro, na perspectiva de alcançar a eternidade.

Esse futuro é possibilitado por meio da tradição, em que as crenças e os costumes passam de geração para geração. Vale ressaltar que a Figura 4 se refere ao depoimento de uma integrante das Ganhadeiras que tem 11 anos de idade. 


\section{Figura 4 - Postagem das Ganhadeiras de Itapuã com depoimento de uma integrante}

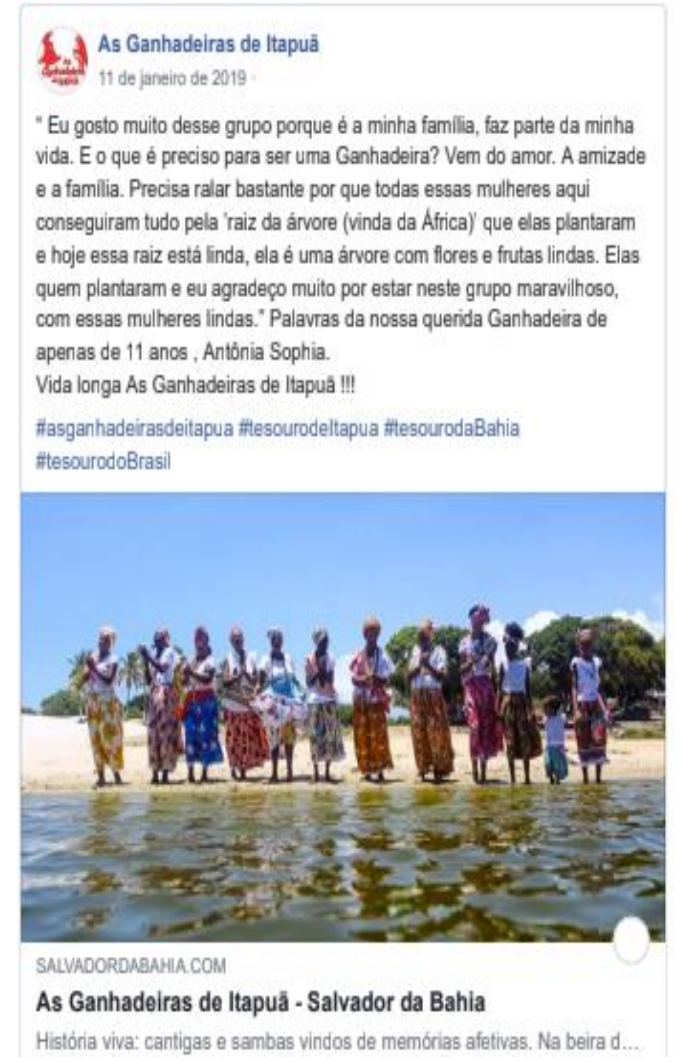

Fonte: https://www.facebook.com/AsGanhadeirasdeltapua/

A fala da Ganhadeira, apresentada na Figura 4, demonstra que os valores afetivos possibilitam a apropriação dos elementos constituintes da identidade e dos saberes de seu povo. Ao demonstrar empoderamento, por meio do dispositivo de comunicação, ela se reconhece como pertencente ao seu meio e fortalece a empatia, visto que os sujeitos podem compreender a história de vida do outro e reconhecer e respeitar as diferenças. Nesse sentido, a web social e seus dispositivos de comunicação podem ser fortes aliados nessa interação, ampliando o processo de comunicação e de compartilhamento do conhecimento.

Pode-se inferir uma postura protagonista das Ganhadeiras de Itapuã, ao realizarem ações que, nesta pesquisa, são entendidas como de mediação cultural, pois apresentam, celebram e reforçam indícios identitários do povo negro, por meio da contação de histórias apresentadas nas músicas, nas danças, nos ritmos, nos figurinos etc., conforme observado na Figura 5. 


\section{Figura 5 - Postagem das Ganhadeiras de Itapuã sobre o evento de celebração dos 15 anos do Grupo}

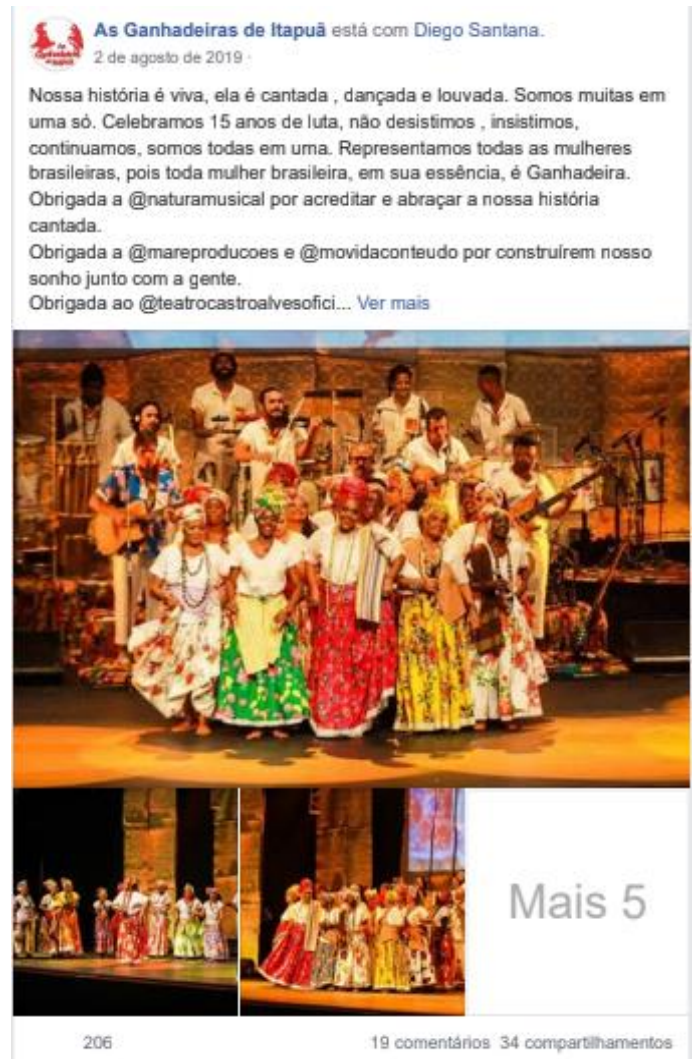

Fonte: https://www.facebook.com/AsGanhadeirasdeltapua/

A identidade das Ganhadeiras de Itapuã e a garantia de sua subsistência também são mantidas por meio das tradições, do relato de suas histórias de vida e de suas experiências, que, associados à mediação cultural, possibilitam o processo de mediação da leitura. Na Figura 6, as Ganhadeiras contam as histórias de suas ancestrais para as crianças, evidenciando a relação entre a mediação cultural e a mediação da leitura. Essa é uma forma de preservar e fortalecer a consciência da memória do povo negro. Por essa razão, são muito importantes ações de mediação da cultura e da leitura para o acesso às informações e a construção de conhecimentos revestidos de valores culturais. 
Figura 6 - Postagem das Ganhadeiras de Itapuã sobre uma atividade realizada em uma escola

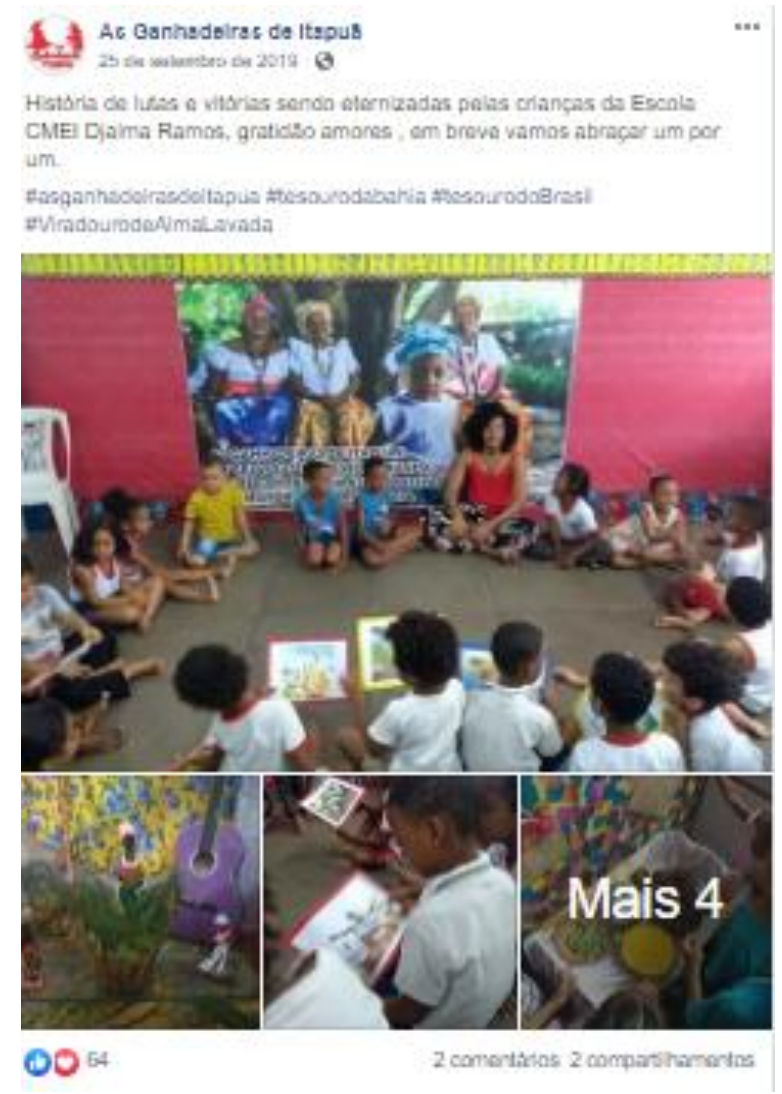

Fonte: https://www.facebook.com/AsGanhadeirasdeltapua/

A força das mulheres afrodescendentes Ganhadeiras de Itapuã é demonstrada nas experiências de seu trabalho, por meio do qual elas podem adquirir recursos para alcançar seus objetivos. Isso fortalece o sentimento de pertencimento entre os adeptos das práticas religiosas afrodescendentes e mantém os traços de sua ancestralidade. Esses são vestígios identitários preservados e reverenciados por meio das músicas que contam, transmitem e permitem a leitura da história de vida, individual e coletiva, desses sujeitos protagonistas. Nesse contexto, a relevância as letras das músicas, as danças e os elementos que compõem os figurinos das Ganhadeiras de Itapuã são muito importantes, porque contam suas histórias e reafirmam a identidade desse grupo social. 
Figura 7 - Postagem das Ganhadeiras de Itapuã em comemoração aos 15 anos de formação do Grupo

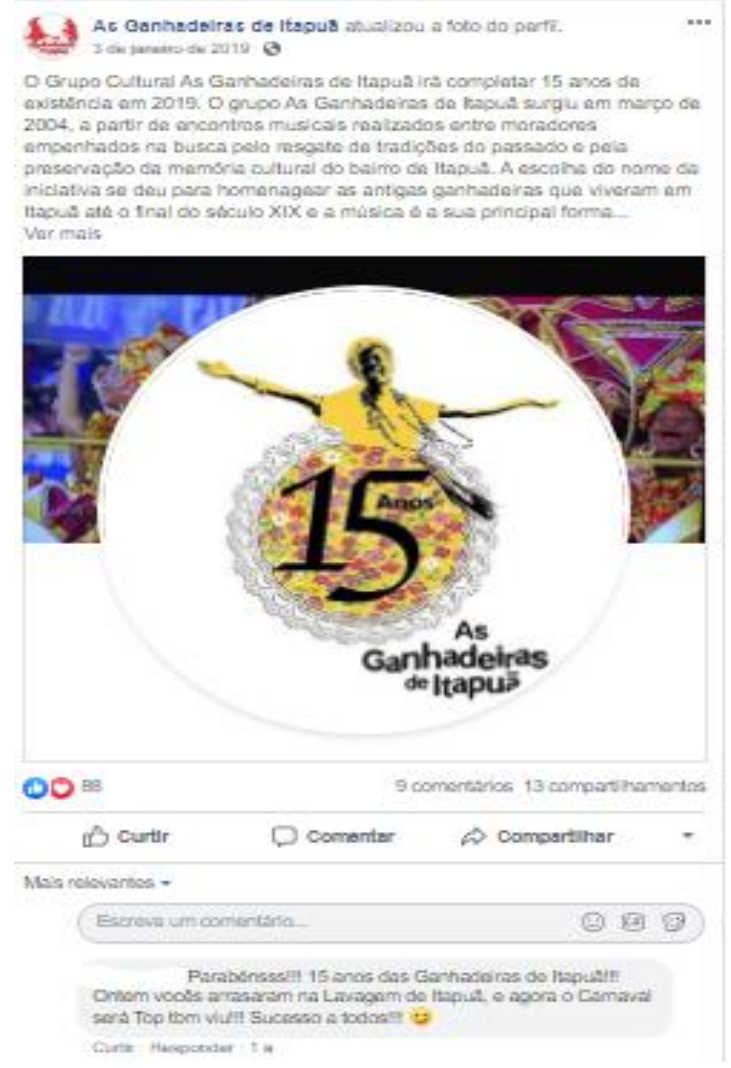

Fonte: https://www.facebook.com/AsGanhadeirasdeltapua/

A musicalidade é um dos aspectos que possibilitam ao Grupo de Ganhadeiras de Itapuã ser reconhecido, não apenas por meio dos prêmios, mas também dos sujeitos de sua comunidade, pela preservação de seus traços identitários e memorialísticos, como membros pertencentes ao Bairro de Itapuã, Salvador - BA, em que suas práticas sociais, como o artesanato, a culinária e os saberes de suas ancestrais, são desenvolvidas e constituem a memória coletiva. As letras das músicas, divulgadas por meio dos vídeos postados na página do Facebook, contam a história de luta e de resistência das mulheres negras e de seu povo como também descrevem, reverenciam e rememoram o passado, suas práticas sociais e sua fé, em um processo de preservação e disseminação dos seus traços identitários e memorialísticos.

A análise da página do Facebook das Ganhadeiras de Itapuã e a observação de alguns registros apresentados nesta comunicação reforçam a importância dos dispositivos de comunicação da web social para ampliar a 
mediação cultural, que fortalece os traços identitários e memorialísticos do meio e de seu povo. Entretanto, é preciso analisar criticamente os enunciados presentes nessas postagens, porque são constituídos de maneira intencional, carregados de sentido e com o objetivo de representar o produtor. Assim, esse dispositivo de comunicação foi elaborado em meio às práticas da escrita de si, portanto, um processo de seleção e preservação da autoimagem.

\title{
5 CONSIDERAÇÕES
}

\author{
"Itapuã, dos coqueirais \\ Itapuã, do abaeté \\ Itapuã de dorival e vinícius \\ Dos baianos, e do acarajé." \\ Passado e Presente \\ As Ganhadeiras de Itapuã
}

Em tempos em que as barreiras ideológicas, econômicas e políticas são postas, é preciso rememorar as histórias de sujeitos que resistiram a essas dificuldades e atuaram em seu meio, transformando a si mesmo e aos outros. As Ganhadeiras de Itapuã representam, especialmente para a comunidade de Itapuã e para o povo baiano, um símbolo de luta e de força, razão por que se tornaram uma referência cultural. A música, a dança, a culinária, o artesanato, a fé e a afetividade são alguns dos elementos que estão materializados nos conteúdos disponíveis em sua página do Facebook. Pode-se inferir que existe uma ação consciente de disseminar a memória e as práticas dessas mulheres que atuam como protagonistas culturais e sociais.

Quando o agente mediador utiliza o dispositivo de comunicação na web, que potencializa a mediação cultural para além do território baiano, possibilita que se reconheçam as diferentes manifestações identitárias e memorialísticas de sua estrutura sociocultural e a construção dialógica no âmbito da diversidade de pensamento, de ideologias e de crenças. Assim, o mediador cultural não negligencia a existência dos embates, das diferenças e dos conflitos nem se furta de se posicionar ativamente e de criar estratégias de interação, o que possibilita o espaço de fala e de reflexão e evidencia os sentidos comuns, a compreensão e a valorização da história de vida do outro e o reconhecimento e o respeito às 
diferenças.

As palavras mulher, negra, trabalhadora e vencedora podem ser representativas de muitas publicações disponibilizadas na página das Ganhadeiras de Itapuã que buscam evidenciar o empoderamento e a força da mulher negra na constituição da sociedade brasileira. $O$ autorreconhecimento das Ganhadeiras de Itapuã para a cultura brasileira e a consciência coletiva de mulheres e de crianças é constatado em suas ações, suas palavras e seus gestos, disponibilizados no dispositivo de comunicação da web. Esses conteúdos objetivam fortalecer as mulheres e desenvolver a sororidade. Assim, rompendo as barreiras do lugar e do tempo, existe uma busca pela valorização identitária e pelos aspectos memorialísticos, não somente do povo negro, mas, também, principalmente, da mulher negra.

O estudo mostrou que o dispositivo de comunicação da web é um ambiente propício para mediar a cultura, a informação e a leitura, o que demonstra uma convergência dessas ações. Nas próximas etapas desta pesquisa, será realizada uma pesquisa de campo com as Ganhadeiras de Itapuã para verificar sua consciência quanto à relevância de realizar tais ações para preservar e disseminar os aspectos identitários e memorialísticos, tanto no ambiente físico quanto no digital e investigar se existe um processo intencional na seleção das informações, que revelam o sentido e o objetivo de representar o produtor, evidenciando as práticas da escrita de si, portanto, se existe processo de seleção e de preservação da autoimagem, por meio do dispositivo de comunicação da web social.

\section{REFERÊNCIAS}

AS GANHADEIRAS de Itapuã. Salvador: TV UFBA, 2015. 1 vídeo (29:27min). Disponível em: https://www.youtube.com/watch?v=fx6586NGVb8. Acesso em: 26 out. 2020.

CANDAU, J. Antropologia da memória. Lisboa: Instituto Piaget, 2013.

CANDAU, J. Memória e Identidade. São Paulo: Contexto, 2012. 
DODEBEI, V. L. D. L. M. O sentido e o significado de documento para Memória Social. 1997. 185f. Tese (Doutorado em Comunicação e Cultura) Escola de Comunicação da UFRJ, Rio de Janeiro, 1997.

FOUCAULT, M. A arqueologia do saber. 3 ed. Rio de Janeiro: Forense, 1987.

GIL, A. C. Como elaborar projetos de pesquisa. 4 ed. São Paulo: Atlas, 2002.

PERROTTI, E. Mediação cultural: alguns procedimentos. In: SALCEDO, D. A. Mediação Cultural. São Carlos: Pedro \& João Editores, 2016. 252p.

PIERUCCINI, I. Ordem informacional dialógica: mediação como apropriação da informação. In: ENCONTRO NACIONAL DE PESQUISA EM CIÊNCIA DA INFORMAÇÃO, 8., 2007, Salvador. Anais... Salvador: Universidade Federal da Bahia, 2007.

POLLAK, M. Memória e Identidade Social. Estudos Históricos, Rio de Janeiro, v. 5, n. 10, p. 200-212, 1992.

PRIMO, A. O aspecto relacional das interações na Web 2.0. E-Compós, Brasília, v. 9, p. 1-21, 2007. Disponível em: http://www.ufrgs.br/limc/PDFs/web2.pdf. Acesso em: 20 jan. 2019.

RIBEIRO, A.; LEITE, R. S.; LOPES, H. E. G. Análise do uso das redes sociais em bibliotecas universitárias brasileiras. Rev. digit. bibliotecon. cienc. inf., Campinas, v. 12, n. 3, p. 5-27, set./dez. 2014. Disponível em: https://periodicos.sbu.unicamp.br/ojs/index.php/rdbci/article/view/1591. Acesso em: 8 out. 2019.

\title{
MEMORIALISTIC AND IDENTITY ASPECTS PRESENT IN THE STATEMENTS OF GANHADEIRAS DE ITAPUÃ: REDEFINITION OF CULTURAL MEDIATION IN THE WEB COMMUNICATION DEVICE
}

\begin{abstract}
Introduction: Communication devices favor cultural mediation, because they enhance, in addition to time and geographic space, access to information, loaded with meanings and memorialistic value and which constitute the history of the subjects. Objective: which aimed to investigate whether the statements available on the Ganhadeiras de Itapuã web communication device contribute to re-signify the identity and memorial features of the environment in which their social practices are developed and to mediate culture. Methodology: As for the data collection procedures, the in direct observation technique was adopted to identify the content available on Facebook of Ganhadeiras de Itapuã. The sample was from January to December 2019 posts. It was selected the most representative posts of the social context in which these women are inserted. The data were analyzed using the qualitative approach, which favored the process of interpreting
\end{abstract}


the collected data. Results: It was found that the communication device of the social web of Ganhadeiras de Itapuã potentiates cultural mediation beyond the Bahian territory, as they contribute to the identity and memorialistic manifestations of this group to be recognized and, consciously, promote dialogical construction within diversity of thoughts, ideologies and beliefs. Conclusions: The study showed that the communication device of Ganhadeiras de Itapuã is an ideal environment to mediate culture, information and reading, as well as to reveal traces of memory and identity of black women.

Descriptors: Memory. Identity. Cultural mediation. Web communication device. Ganhadeiras de Itapuã.

\title{
ASPECTOS DE IDENTIDAD Y MEMORIALISMO PRESENTES EN LAS DECLARACIONES DE GANHADEIRAS DE ITAPUÃ: REDEFINICIÓN DE MEDIACIÓN CULTURAL EN EL DISPOSITIVO DE COMUNICACIÓN WEB
}

\begin{abstract}
RESUMEN
Introducción: Los dispositivos de comunicación favorecen la mediación cultural, ya que mejoran, además del tiempo y el espacio geográfico, el acceso a la información, cargada de significados y valores conmemorativos y que constituyen la historia de los temas. Objetivo: investigar si las declaraciones disponibles en el dispositivo de comunicación web Ganhadeiras de Itapuã contribuyen a volver a significar la identidad y las características conmemorativas del entorno en el que se desarrollan sus prácticas sociales y mediar en la cultura. Metodología: En cuanto a los procedimientos de recopilación de datos, se adoptó la técnica de observación indirecta para identificar el contenido disponible en Facebook de Ganhadeiras de Itapuã. La muestra fue de enero a diciembre de 2019. Se seleccionaron los puestos más representativos del contexto social en el que se insertan estas mujeres. Los datos se analizaron utilizando el enfoque cualitativo, que favoreció el proceso de interpretación de los datos recopilados. Resultados: Se descubrió que el dispositivo de comunicación de la red social de Ganhadeiras de Itapuã potencia la mediación cultural más allá del territorio bahiano, ya que contribuyen a que la identidad y las manifestaciones conmemorativas de este grupo sean reconocidas y, conscientemente, promuevan la construcción dialógica dentro de la diversidad de pensamientos, ideologías y creencias. Conclusiones: El estudio mostró que el dispositivo de comunicación de Ganhadeiras de Itapuã es un entorno ideal para mediar en la cultura, la información y la lectura, así como para revelar rastros de memoria e identidad de las mujeres negras.
\end{abstract}

Descriptores: Memoria. Identidad. Mediación cultural. Dispositivo de comunicación web. Ganhadeiras de Itapuã.

Recebido em: 06.04.2020

Aceito em: 13.12 .2020 